Recibido: 2 de noviembre de 2018

Concepto de evaluación: 15 de febrero de 2019

Aprobado: 12 de diciembre de 2019

Artículo de investigación

(C) 2019 Universidad Católica de Colombia.

Facultad de Ciencias

Económicas y Administrativas.

Todos los derechos reservados

* Public Accountant, Universidad de La Salle (Colombia). Specialization in Tax Administration and Management, Universidad Externado de Colombia. Chemical engineering, Universidad Nacional de Colombia. M. Sc. in Nanotechnology and Ph. D. in Chemistry, Universidad Autónoma de Barcelona (Spain). Postdoctorate, Leibniz Institute of Catalysis (Germany). E-mail: ferchogomezv@gmail.com

(D) https://orcid.org//0000-0001-5860-6951

\title{
A simple extension of Rolle's theorem and its relation with multiple internal rates of return (IRR)
}

\section{ABSTRACT}

This paper presents a simple extension of Rolle's Theorem. This extension allows determining the amount of numbers $\xi_{i}$ in which $f^{\prime}\left(\xi_{i}\right)=0$ in a given interval, using the characteristics of the function $f$ in that interval. The extension has been proved, and the geometric interpretation has been presented. Illustrative examples have also been developed for each case that can be obtained by applying the extension. Finally, the study examines the relation of this theorem with the problem of multiple internal rates of return (IRR).

Keywords: Multiple internal rates of return (IRR), Rolle's theorem.

JEL Classification: C02, C20, G00

Cómo citar este artículo / To reference this article / Para citar este artigo:

Gómez-Villarraga, F. (2019). A simple extension of Rolle's theorem and its relation with multiple internal rates of return (IRR). Revista Finanzas y Politica Económica, 11 (2), 241-258. doi: http://dx.doi.org/10.14718/revfinanzpolitecon.2019.11.2.2

\section{Una extensión simple del teorema de Rolle y su relación con múltiples tasas internas de retorno (TIR)}

\section{RESUMEN}

En este artículo se presenta una extensión simple del teorema de Rolle. Esta extensión permite determinar la cantidad de números $\xi_{i}$ en los que $f^{\prime}\left(\xi_{i}\right)=0$ en un intervalo dado utilizando las características de la función $f$ en ese intervalo. La extensión ha sido probada y se presenta la interpretación geométrica. Se han desarrollado ejemplos ilustrativos para cada uno de los casos que se pueden obtener aplicando la extensión. Se presenta la relación de este teorema con el problema de las múltiples tasas internas de retorno (TIR). Rolle.

Palabras clave: múltiples tasas internas de retorno (TIR), teorema de 


\section{Uma simples extensão do teorema de Rolle e sua relação com múltiplas taxas internas de retorno (TIR)}

\section{RESUMO}

Apresenta-se uma simples extensão do teorema de Rolle, a qual permite determinar a quantidade de Números $\xi_{i}$ em que $f^{\prime}\left(\xi_{i}\right)=0$, num intervalo dado, utiliza as características da função nesse intervalo. A extensão foi testada e é apresentada a interpretação geométrica. Exemplos ilustrativos foram desenvolvidos para cada um dos casos que podem ser obtidos a partir da extensão. Além disso, é apresentada a relação desse teorema com o problema das múltiplas taxas internas de retorno.

Palavras-chave: múltiplas taxas internas de retorno (TIR), teorema de Rolle. 


\section{INTRODUCTION}

Rolle's theorem is attributed to Michel Rolle, and named after this French mathematician. He was a member of the French academy who studied the theory of equations. He stated and proved a preliminary version of the theorem by studying methods to locate and limit the roots of polynomials. Later, Lagrange and Cauchy obtained their mean value theorems applying Rolle's theorem to appropriate functions. Mean value theorems relate the values of the function with its derivative or integral and are important in the proof of several calculus theorems. Rolle's theorem is now found in the development of many introductory topics of differential calculus (Martínez de la Rosa, 2008; Pérez-Chavela \& Petakos, 2009; Tan, 2011).

The internal rate of return (IRR) is the discount rate that makes the net present value (NPV) of all cash flows from a specific project equal to zero. IRR is the root (or roots in a multiple case) of the NPV expression. IRR is used in the financial decision process to accept or refuse a project. If a specific project has an IRR greater than the minimum required rate of return, then the project should be accepted (the project adds value). While if the IRR is less than the minimum required rate of return, the project should be refused. Multiple IRRs can be obtained in nonconventional (also called non-normal) cash flows. The non-conventional type is a cash flow pattern in which cash flows change the sign more than once (Cissell et al., 1990; Vélez Pareja, 2002).

This paper states and proves an extension of Rolle's theorem that determines the amount of numbers $\xi_{i}$ in which $f^{\prime}\left(\xi_{i}\right)=0$ in a given interval, using the characteristics of the function $f$ in that interval. This approach has been used to calculate the amount of internal rates of return (IRR) in a non-conventional cash flow.

\section{A SIMPLE EXTENSION OF ROLLE'S THEOREM}

Let the function $f$ be: i. Continuous on a closed interval $[a, b]$.

ii. Continuously differentiable on the open interval $(a, b)$.

iii. The function $f^{\prime}$ is differentiable on the open interval $(a, b)$.

iv. $f(a)=f(b)=c$ (where $c$ is a constant).

v. $f(x) \neq k$ (where $k$ is a constant).

vi. $f_{+}^{\prime}(a) \neq 0$ and $f_{-}^{\prime}(b) \neq 0$.

vii. There are $n>0$ points $d_{i}$ in the open interval $(a, b)$ such that $f^{\prime \prime}\left(d_{1}\right)=f^{\prime \prime}\left(d_{2}\right)=\ldots=f^{\prime \prime}\left(d_{n-1}\right)=$ $f^{\prime \prime}\left(d_{n}\right)=0$ (where $n$ is the number of points $d_{i}$ in the open interval $(a, b)$ such that $f^{\prime \prime}\left(d_{i}\right)$ $=0$ ).

viii. The derivative of $f$ at the points $d_{i}$ is different from zero, $f^{\prime}\left(d_{i}\right) \neq 0(i=1,2, \ldots, n-1, n)$.

ix. The signs of the derivatives of $f$ at the points $d_{i}$ alternate (for $\mathrm{n} \geq 2$ ).

Then:

a. There exist $n-1$ numbers $\xi_{i}$ in the open interval $(a, b)$ such that $f^{\prime}\left(\xi_{1}\right)=f^{\prime}\left(\xi_{2}\right)=\ldots=f^{\prime}\left(\xi_{n-2}\right)$ $=f^{\prime}\left(\xi_{n-1}\right)=0$, as long as:

a.1 The signs of the lateral right-hand derivative evaluated at $a, f_{+}^{\prime}(a)$ and that of the derivative evaluated at the first point $d_{1}, f^{\prime}\left(d_{1}\right)$ are the same, and

a.2 The signs of the derivative evaluated at the last point $d_{n^{\prime}} f^{\prime}\left(d_{n}\right)$ and that of the lateral left-hand derivative evaluated at $b, f_{-}^{\prime}(b)$ are the same.

b. There exist $n$ numbers $\xi_{i}$ in the open interval $(a, b)$ such that $f^{\prime}\left(\xi_{1}\right)=f^{\prime}\left(\xi_{2}\right)=\ldots=f^{\prime}\left(\xi_{n-1}\right)=$ $f^{\prime}\left(\xi_{n}\right)=0$, as long as:

b.1.1 The signs of the lateral right-hand derivative evaluated at $a, f_{+}^{\prime}(a)$ and that of the derivative evaluated at the first point $d_{1}, f^{\prime}\left(d_{1}\right)$ are the same, and

b.2.1 The signs of the derivative evaluated at the last point $d_{n^{\prime}} f^{\prime}\left(d_{n}\right)$ and that of the lateral left-hand derivative evaluated at $b, f_{-}^{\prime}(b)$ are different, or

b.1.2 The signs of the lateral right-hand derivative evaluated at $a, f_{+}^{\prime}(a)$ and that of the derivative evaluated at the first point $d_{1}, f^{\prime}\left(d_{1}\right)$ are different, and 
b.2.2 The signs of the derivative evaluated at the last point $d_{n^{\prime}} f^{\prime}\left(d_{n}\right)$ and that of the lateral left-hand derivative evaluated at $b, f_{-}^{\prime}(b)$ are the same.

c. There exist $n+1$ numbers $\xi_{i}$ in the open interval $(a, b)$ such that $f^{\prime}\left(\xi_{1}\right)=f^{\prime}\left(\xi_{2}\right)=\ldots=f^{\prime}\left(\xi_{n}\right)$ $=f^{\prime}\left(\xi_{n+1}\right)=0$, as long as:

c.1 The signs of the lateral right-hand derivative evaluated at $a, f_{+}^{\prime}(a)$ and that of the derivative evaluated at the first point $d_{1}, f^{\prime}\left(d_{1}\right)$ are different, and

c.2 The signs of the derivative evaluated at the last point $d_{n^{\prime}} f^{\prime}\left(d_{n}\right)$ and that of the lateral left-hand derivative evaluated at $b, f_{-}^{\prime}(b)$ are different.

\section{Corollary}

Let the function $f$ be:

i. Continuous on a closed interval $[a, b]$.

ii. Continuously differentiable on the open interval $(a, b)$.

iii. The function $f^{\prime}$ is differentiable on the open interval $(a, b)$.

iv. $f(a)=f(b)=c$ (where $c$ is a constant).

v. $f(x) \neq k$ (where $k$ is a constant).

vi. $n=0$ there is no point $d$ in the open interval $(a, b)$ such that $f^{\prime \prime}(d)=0, f^{\prime \prime}(x) \neq 0, \forall x \in$ $(a, b)$ (where $n$ is the number of points $d_{i}$ in the open interval $(a, b)$ such that $\left.f^{\prime \prime}\left(d_{i}\right)=0\right)$ Then, there exists one number $\xi$ in the open interval $(a, b)$ such that $f^{\prime}(\xi)=0$.

\section{PROOF OF THE SIMPLE EXTENSION OF ROLLE'S THEOREM}

If $f(x)=k$ for all $x$ in $[a, b]$, then $f^{\prime}(x)=0$ for all $x$ in $(a, b)$; thus, any number between $a$ and $b$ can be considered as $\xi_{i}$. To obtain a finite number of points $\xi_{i}, f(x) \neq k$ (condition $\mathrm{v}$ ).

Since there are $n$ points $d_{i}$ in the interval $(a$, $b$ ) such that $f^{\prime \prime}\left(d_{1}\right)=f^{\prime \prime}\left(d_{2}\right)=\ldots=f^{\prime \prime}\left(d_{n-1}\right)=f^{\prime \prime}\left(d_{n}\right)=0$ (conditions iii and vii), $n+1$ subintervals can be established given by $\left[a, d_{1}\right],\left[d_{1}, d_{2}\right], \ldots,\left[d_{n-1}, d_{n}\right],\left[d_{n}, b\right]$ in the interval $[a, b]$, where: $a<d_{1}<d_{2}<\ldots<d_{n-1}<d_{n}$ $<b .\left[d_{1}, d_{2}\right],\left[d_{2}, d_{3}\right], \ldots,\left[d_{n-2}, d_{n-1}\right],\left[d_{n-1}, d_{n}\right]$ are denoted as interior intervals ( $n-1$ subintervals) and $\left[a, d_{1}\right]$, $\left[d_{n}, b\right]$ as exterior intervals (2 subintervals). First, the interior intervals are considered as follows.

As $f$ is continuous on the interval $[a, b]$ (condition i), $f$ is also continuous on the interior subintervals $\left[d_{1}, d_{2}\right],\left[d_{2}, d_{3}\right], \ldots,\left[d_{n-2}, d_{n-1}\right],\left[d_{n-1}, d_{n}\right]$. Then, by the extreme value theorem, $f$ has an absolute maximum and minimum value in each interior subinterval $\left[d_{1}, d_{2}\right],\left[d_{2}, d_{3}\right], \ldots,\left[d_{n-2}, d_{n-1}\right],\left[d_{n-1}, d_{n}\right]$. The derivative $f^{\prime}$ is continuous on the open interval $(a, b)$ since $f$ is continuously differentiable on this interval (condition ii). Thus, $f^{\prime}$ is continuous on each interior subinterval $\left[d_{1}, d_{2}\right],\left[d_{2}, d_{3}\right], \ldots,\left[d_{n-2}, d_{n-1}\right],\left[d_{n-1}, d_{n}\right]$. Under these considerations, the intermediate value theorem can be applied to each interior subinterval. The corollary called Bolzano's theorem is used in this point. Since it is assumed that the signs of the derivatives of $f$ at the points $d_{i}$ alternate (conditions viii and ix), the continuous derivative $f^{\prime}$ has values of opposite sign evaluated at the extremes of the interval $d_{j}$ and $d_{j+1}$, then the derivative $f^{\prime}$ has a zero (root) in the interval $\left(d_{j}, d_{j+1}\right)$ In addition, since there are no points $d_{i}$ in each interior subinterval $\left(d_{1}, d_{2}\right),\left(d_{2}, d_{3}\right), \ldots,\left(d_{n-2}, d_{n-1}\right),\left(d_{n-1}, d_{n}\right)$, the graph of $f$ is concave upward or concave downward in each interval. Then, $f$ has only one extreme value at $\xi_{i}$ in each subinterval. Thus, there exist $n-1$ numbers $\xi_{i}$ in the $n-1$ subintervals $\left(d_{1}, d_{2}\right),\left(d_{2}, d_{3}\right), \ldots,\left(d_{n-2}, d_{n-1}\right)$, $\left(d_{n-1}, d_{n}\right)$ such that $f^{\prime}\left(\xi_{i}\right)=0$ (Figure 1) (Tan, 2011; Leithold, 1995).

On the other hand, the exterior intervals are considered $\left[a, d_{1}\right],\left[d_{n}, b\right]$. There are no points $d_{i}$ in the subintervals $\left(a, d_{1}\right),\left(d_{n}, b\right)$. The derivative $f^{\prime}$ is continuous on the open interval $(a, b)$ since $f$ is continuously differentiable on this interval (condition ii). Thus, $f^{\prime}$ is continuous on each exterior subinterval $\left(a, d_{1}\right],\left[d_{n^{\prime}} b\right)$. The following situations can be obtained.

\section{Part a}

Since there is no change in the sign of the derivative on these intervals, there are no numbers $\xi_{i}$ in which $f^{\prime}\left(\xi_{i}\right)=0$. Adding up the numbers $\xi_{i}$ of 
Figure 1.

$n-1$ numbers $\xi_{i}$ in the $n-1$ subintervals $\left(d_{1^{\prime}} d_{2}\right),\left(d_{2^{\prime}} d_{3}\right), \ldots,\left(d_{n-2}, d_{n-1}\right),\left(d_{n-1}, d_{n}\right)$, such tht $f^{\prime}\left(\xi_{i}\right)=0$

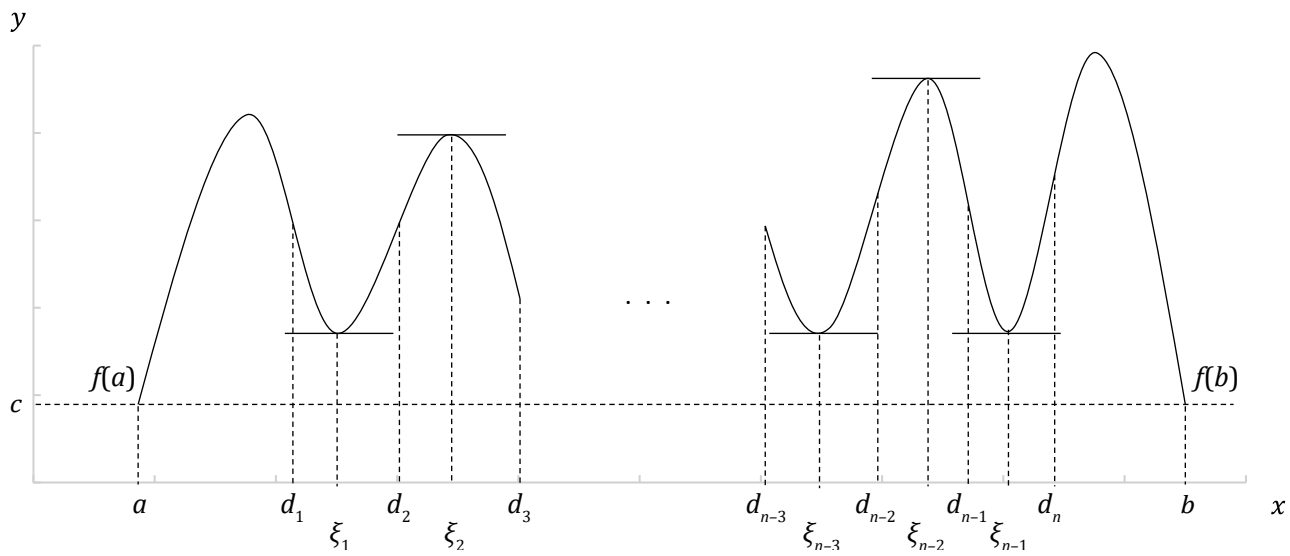

Source: Authors' calculations.

Figure 2.

There are no numbers $\xi_{i}$ in the subintervals $\left(a, d_{1}\right),\left(d_{n^{\prime}} b\right)$ such that $f^{\prime}(\xi i)=0$

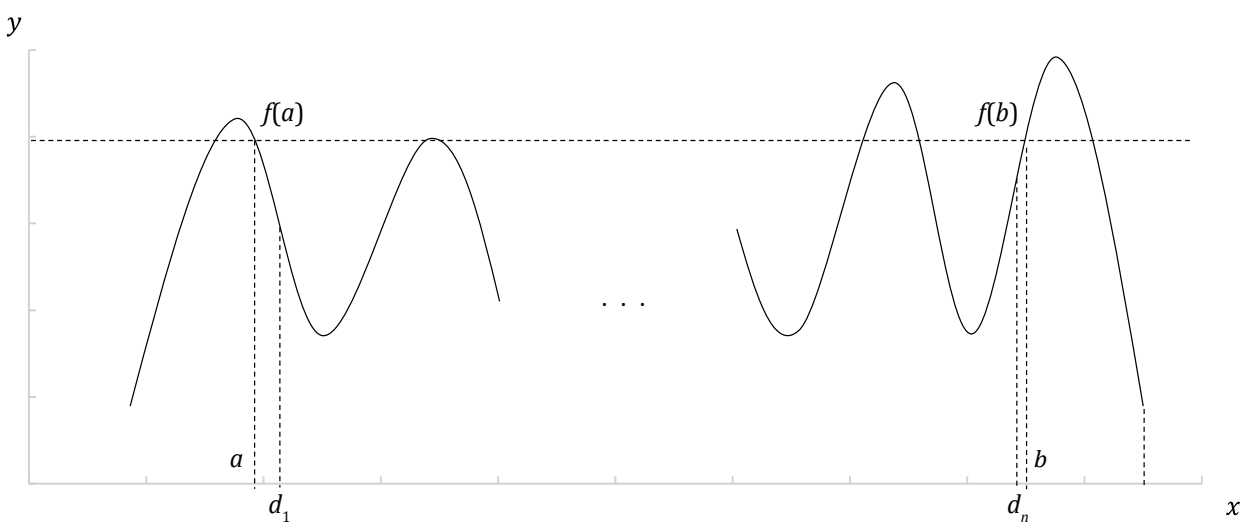

Source: Authors' calculations.

the interior and exterior intervals, there are obtained $n-1+0=n-1$ numbers $\xi_{i}$ in the interval $(a$, $b$ ) such that $f^{\prime}\left(\xi_{i}\right)=0$ (Figure 2).

\section{Part b}

Since there is no change in the sign of the derivative on one of the two intervals, there is no number $\xi_{i}$ in which $f^{\prime}\left(\xi_{i}\right)=0$ in the aforementioned interval. But if there is a change in the sign of the derivative on the other interval (Bolzano's theorem), and since it is assumed that $f_{+}^{\prime}(a) \neq 0$ and $f_{-}^{\prime}(b) \neq 0$ (condition vi), there is one number $\xi_{i}$ in the interval such that $f^{\prime}\left(\xi_{i}\right)=0$. Adding up the numbers $\xi_{i}$ of the interior and exterior intervals, there are obtained $n-1+1=n$ numbers $\xi_{i}$ in the interval $(a, b)$ such that $f^{\prime}\left(\xi_{i}\right)=0$ (Figure 3 ).

\section{Partc}

Since there is a change in the sign of the derivative on both of the intervals (Bolzano's theorem), and since it is assumed that $f_{+}^{\prime}(a) \neq 0$ and $f_{-}^{\prime}(b) \neq 0$ (condition vi), there is one number $\xi_{i}$ in each interval such that $f^{\prime}\left(\xi_{i}\right)=0$. Adding up the numbers $\xi_{i}$ of the interior and exterior intervals, there are obtained $n-1+2=n+1$ numbers $\xi_{i}$ in the interval $(a, b)$ such that $f^{\prime}\left(\xi_{\mathrm{i}}\right)=0$ (Figure 4$)$. 
Figure 3.

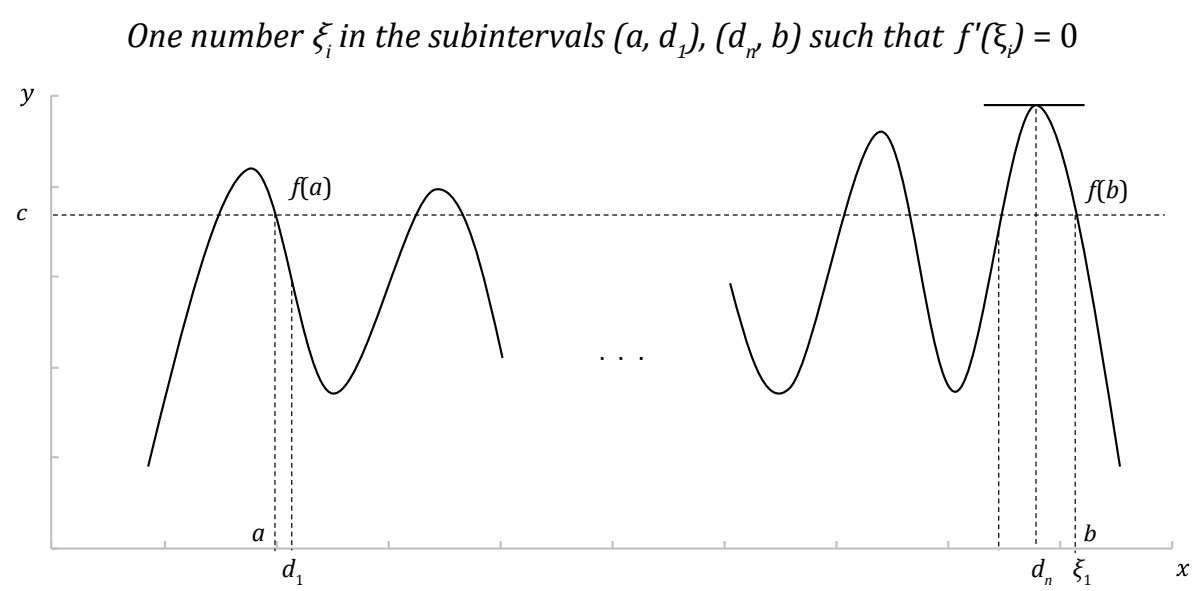

Source: Authors' calculations.

Figure 4.

Two numbers $\xi_{i}$ in the subintervals $\left(a, d_{1}\right),\left(d_{n^{\prime}}, b\right)$ such that $f^{\prime}\left(\xi_{i}\right)=0$

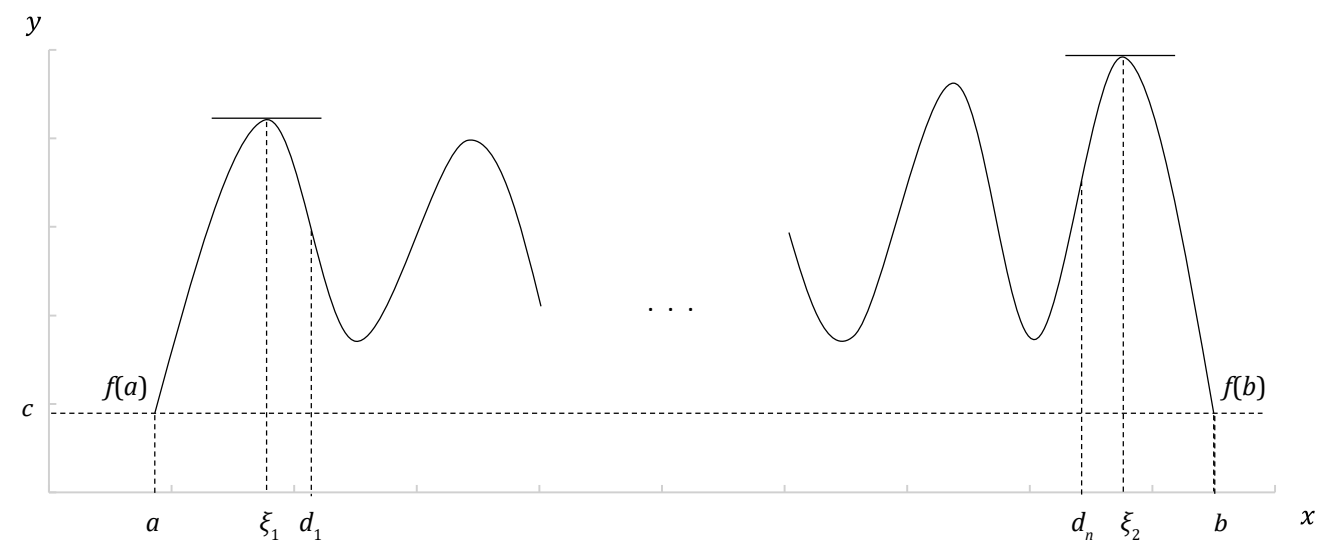

Source: Authors' calculations.

\section{Corollary}

Similarly, if $f(x)=k$ for all $x$ in $[a, b]$. Then, $f^{\prime}(x)=0$ for all $x$ in $(a, b)$; thus, any number between $a$ and $b$ can be considered as $\xi_{i}$. To obtain a finite number of points $\xi_{i^{\prime}} f(x) \neq k$ (condition $\mathrm{v}$ ).

$f(x) \neq c$ for any $x$ in $(a, b)$. Under this consideration, there must be a number $x$ in $(a, b)$ where $f(x)>c$ or $f(x)<c$. Since $f$ is continuous on $[a$, $b]$ (condition i), the extreme value theorem implies that $f$ attains an absolute maximum or minimum value at some number $\xi$ in $[a, b]$. The number $\xi$ cannot be an endpoint because $f(a)=f(b)=c$ (condition iv), and it is assumed that $f(x)>c$ or $f(x)<c$ for some number $x$ in $(a, b)$. Therefore, $\xi$ must be in $(a, b)$. Since $f$ is differentiable on $(a$, $b$ ) (condition ii), $f^{\prime}(\xi)$ exists, and by Fermat's theorem $f^{\prime}(\xi)=0$ (Tan, 2011). In addition, since there is no point $d$ in the interval $(a, b)$ such that $f^{\prime \prime}(d)=0$ (conditions iii and vi), the graph of $f$ is concave upward or concave downward in the interval. Then, $f$ has only one extreme value at $\xi$. Thus, there exists one number $\xi$ in the interval $(a, b)$ such that $f^{\prime}(\xi)=0$ (Figure 5). 


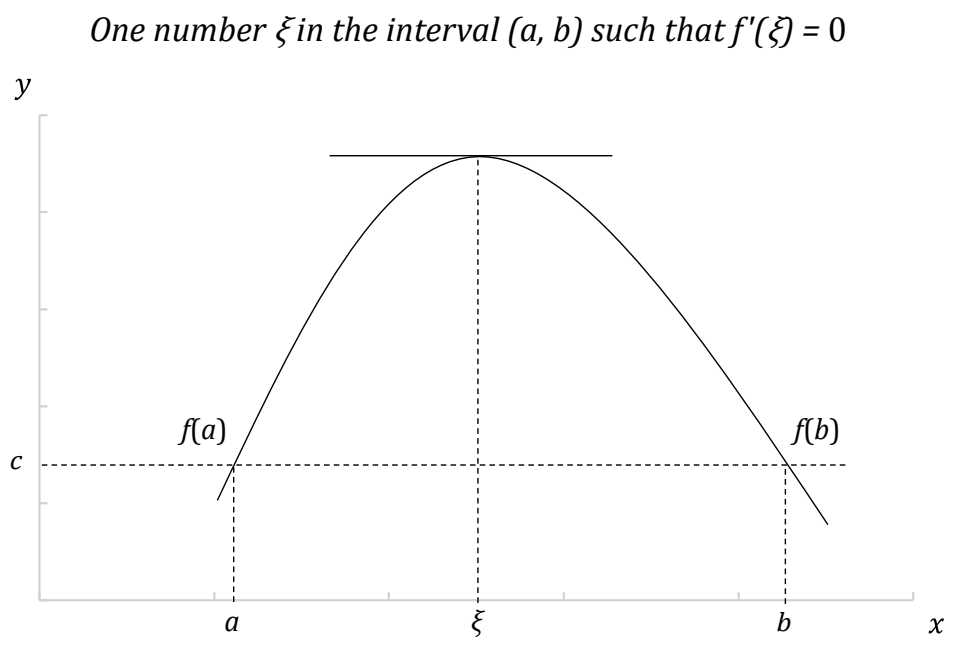

Source: Authors' calculations.

The simple extension of Rolle's theorem and its corollary allow determining the amount of points in which the derivative of a function is equal to zero in a given interval, using the characteristics of the function in that interval. The corollary is proved using a similar deduction to the theorem. The corollary considers that there are no points in the open interval such that the second derivative of the function is zero. The main theorem only takes into account cases where there exist points where the values of the second derivative are equal to zero. Illustrative examples of the different parts of the main theorem and the corollary are presented in the following sections. A special section is dedicated to the relation of the theorem to multiple internal rates of return (IRR).

\section{ILLUSTRATIVE EXAMPLES}

\section{Part a}

Let $f$ be:

$$
f(x)=\sin x
$$

The derivative of $f$ is:

$$
f^{\prime}(x)=\cos x
$$

The derivative of $f^{\prime}$ is:

$$
f^{\prime \prime}(x)=-\sin x
$$

$f^{\prime}(x)$ and $f^{\prime \prime}(x)$ exist and are continuous for all values of $x$. $f$ and $f^{\prime}$ are differentiable on the interval $(-\infty,+\infty)$ and therefore continuous on $(-\infty,+\infty)$. Thus, the conditions (i), (ii) and (iii) of the theorem are satisfied at any interval. Any interval in which the condition (iv) is fulfilled is determined as follows:

$$
\begin{aligned}
& \sqrt{3} / 2=\sin x \\
& x=\sin ^{-1} \sqrt{3} / 2 \\
& x=\pi / 3+2 \pi n \cup 2 \pi / 3+2 \pi n, n \in \mathbb{Z} \\
& \text { Choosing } a=2 \pi / 3 \text { and } b=13 \pi / 3 .
\end{aligned}
$$

The condition (v) is satisfied. Since $f$ is differentiable on the interval $(-\infty,+\infty)$, the lateral derivatives evaluated at the extremes of the interval of the condition (vi) are given by:

$$
\begin{aligned}
& f_{+}^{\prime}(2 \pi / 3)=f_{-}^{\prime}(2 \pi / 3)=f^{\prime}(2 \pi / 3) \\
& f^{\prime}(2 \pi / 3)=\cos 2 \pi / 3=-1 / 2 \\
& f_{-}^{\prime}(13 \pi / 3)=f_{+}^{\prime}(13 \pi / 3)=f^{\prime}(13 \pi / 3) \\
& f^{\prime}(13 \pi / 3)=\cos 13 \pi / 3=1 / 2
\end{aligned}
$$


Therefore, the condition (vi) is fulfilled. From the derivative of $f^{\prime}$ :

$$
f^{\prime \prime}(x)=-\sin x
$$

The points $d_{i}$ in the openinterval $(2 \pi / 3,13 \pi / 3)$ such that $f^{\prime \prime}\left(d_{i}\right)=0$ are calculated:

$$
\begin{aligned}
0 & =-\sin x \\
0 & =\sin x \\
x & =\sin ^{-1} 0 \\
x & =n \pi, n \in \mathbb{Z} \\
d_{1}=\pi, d_{2} & =2 \pi, d_{3}=3 \pi, d_{4}=4 \pi .
\end{aligned}
$$

Thus, there are $n=4$ points $d_{i}$ in the interval $(2 \pi / 3,13 \pi / 3)$ (condition (vii)). The derivative at the points $d_{i}$ is determined as:

$$
\begin{array}{r}
f^{\prime}(\pi)=f^{\prime}(3 \pi)=\cos \pi=\cos 3 \pi=-1 \\
f^{\prime}(2 \pi)=f^{\prime}(4 \pi)=\cos 2 \pi=\cos 4 \pi=1
\end{array}
$$

The condition (viii) is satisfied since the derivative of $f$ at the points $d_{i}$ is different from zero, $f^{\prime}\left(d_{i}\right) \neq 0(\mathrm{i}=1,2,3,4)$.
The signs of the derivatives of $f$ at the points $d_{i}$ alternate (condition (ix)). $f^{\prime}(\pi)<0, f^{\prime}(2 \pi)>0, f^{\prime}(3 \pi)<0, f(4 \pi)>0$

Then, there exist 4-1=3 numbers $\xi_{i}$ in the interval $(2 \pi / 3,13 \pi / 3)$ such that $f^{\prime}\left(\xi_{1}\right)=f^{\prime}\left(\xi_{2}\right)=f^{\prime}\left(\xi_{3}\right)=0$, since:

The signs of the lateral right-hand derivative evaluated at $2 \pi / 3, f_{+}^{\prime}(2 \pi / 3)<0$ and that of the derivative evaluated at the first point $\pi, f^{\prime}(\pi)<0$ are the same, and

The signs of the derivative evaluated at the last point $4 \pi, f^{\prime}(4 \pi)>0$ and that of the lateral le$\mathrm{ft}$-hand derivative evaluated at $13 \pi / 3, f_{-}^{\prime}(13 \pi / 3)>0$ are the same.

The three numbers $\xi_{i}$ in the interval $(2 \pi / 3,13 \pi / 3)$ are given by:

$$
\begin{aligned}
f^{\prime}(x) & =\cos x=0 \\
x & =\cos ^{-1} 0 \\
x & =\pi / 2+n \pi, n \in \mathbb{Z}
\end{aligned}
$$

Thus, $\xi_{1}=3 \pi / 2, \xi_{2}=5 \pi / 2, \xi_{3}=7 \pi / 2$.

Figure 6.

Graph off $(x)=\sin x$ and the horizontal tangent lines at the points where $\xi_{1}=3 \pi / 2, \xi_{2}=5 \pi / 2, \xi_{3}=7 \pi / 2$

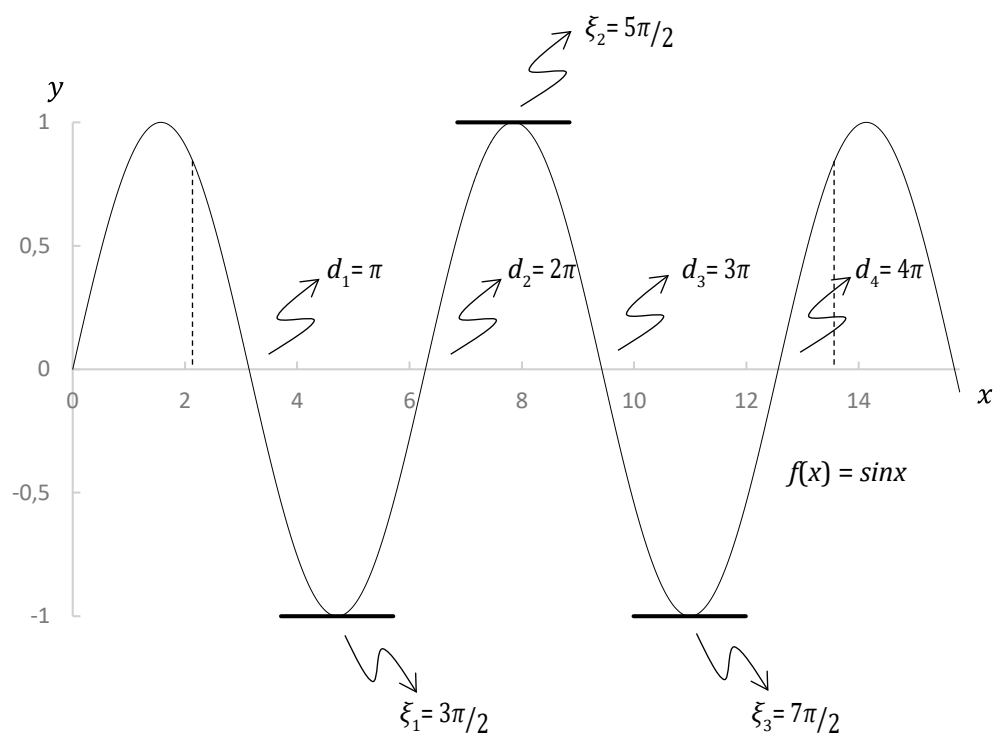

Source: Authors' calculations. 
Figure 6 shows the graph of $f$ and the horizontal tangent lines at the points where $\xi_{1}=3 \pi / 2, \xi_{2}=5 \pi / 2, \xi_{3}=7 \pi / 2$.

\section{Part b}

Let $f$ be:

$$
f(x)=x^{3}-2 x^{2}-x+2
$$

The derivative of $f$ is:

$$
f^{\prime}(x)=3 x^{2}-4 x-1
$$

The derivative of $f^{\prime}$ is:

$$
f^{\prime \prime}(x)=6 x-4
$$

$f^{\prime}(x)$ and $f^{\prime \prime}(x)$ exist and are continuous for all values of $x$. $f$ and $f^{\prime}$ are differentiable on the interval $(-\infty,+\infty)$ and therefore continuous on $(-\infty,+\infty)$. Thus, the conditions (i), (ii) and (iii) of the theorem are satisfied at any interval. Any interval in which the condition (iv) is fulfilled is determined as follows:

$$
\begin{aligned}
-1 / 3 & =x^{3}-2 x^{2}-x+2 \\
0 & =x^{3}-2 x^{2}-x+7 / 3 \\
x_{1} & =-1.053, x_{2}=1.188, x_{3}=1.866
\end{aligned}
$$

Choosing $a=-1.053$ and $\mathrm{b}=1.188$.

The condition (v) is satisfied. Since $f$ is differentiable on the interval $(-\infty,+\infty)$, the lateral derivatives evaluated at the extremes of the interval of the condition (vi) are given by:

$$
\begin{aligned}
f_{+}^{\prime}(-1.053) & =f_{-}^{\prime}(-1.053)=f^{\prime}(-1.053) \\
f^{\prime}(-1.053) & =3(-1.053)^{2}-4(-1.053)-1=6.538 \\
f_{-}^{\prime}(1.188) & =f_{+}^{\prime}(1.188)=f^{\prime}(1.188) \\
f^{\prime}(1.188) & =3(1.188)^{2}-4(1.188)-1=-1.518
\end{aligned}
$$

Therefore, the condition (vi) is fulfilled. From the derivative of $f^{\prime}$ :

$$
f^{\prime \prime}(x)=6 x-4
$$

The points $d_{i}$ in the open interval $(-1.053,1.188)$ such that $f^{\prime \prime}\left(d_{i}\right)=0$ are calculated:

$$
\begin{aligned}
& 0=6 x-4 \\
& x=2 / 3
\end{aligned}
$$

$d_{1}=2 / 3$. Thus, there is $n=1$ point $d$ in the interval $(-1.053,1.188)$ (condition (vii)). The derivative at the point $d$ is determined:

$$
f^{\prime}(2 / 3)=3(2 / 3)^{2}-4(2 / 3)-1=-2.333
$$

The condition (viii) is satisfied since the derivative of $f$ at the point $d$ is different from zero, $f^{\prime}\left(d_{i}\right) \neq 0(i=1)$.

$d_{1}=2 / 3$ are both the first and the last point $d$. The condition (ix) is not applicable.

Then, there exists one number $\xi_{i}$ in the interval $(-1.053,1.188)$ such that $f^{\prime}\left(\xi_{1}\right)=0$, since:

The signs of the lateral right-hand derivative evaluated at $-1.053, f_{+}^{\prime}(-1.053)>0$ and that of the derivative evaluated at the first point $2 / 3$, $f^{\prime}(2 / 3)<0$ are different, and

The signs of the derivative evaluated at the last point $2 / 3, f^{\prime}(2 / 3)<0$ and that of the lateral lefthand derivative evaluated at 1.188, $f_{-}^{\prime}(1.188)<0$ are the same.

The number $\xi_{i}$ in the interval $(-1.053,1.188)$ is given by:

$$
\begin{aligned}
f^{\prime}(x) & =3 x^{2}-4 x-1=0 \\
x & =\frac{4 \pm \sqrt{16+12}}{6} \\
x & =\frac{4 \pm 2 \sqrt{7}}{6}=\frac{2 \pm \sqrt{7}}{3} \\
x_{1} & =2-\sqrt{7} / 3, x_{2}=2+\sqrt{7} / 3 \\
\text { Thus, } \xi_{1} & =2-\sqrt{7} / 3 .
\end{aligned}
$$

Figure 7 shows the graph of $f$ and the horizontal tangent line at the point where $\xi_{1}=2-\sqrt{7} / 3$.

\section{Partc}

Let $f$ be:

$$
f(x)=\sin x
$$

The derivative of $f$ is:

$$
f^{\prime}(x)=\cos x
$$

The derivative of $f^{\prime}$ is:

$$
f^{\prime \prime}(x)=-\sin x
$$


Figure 7.

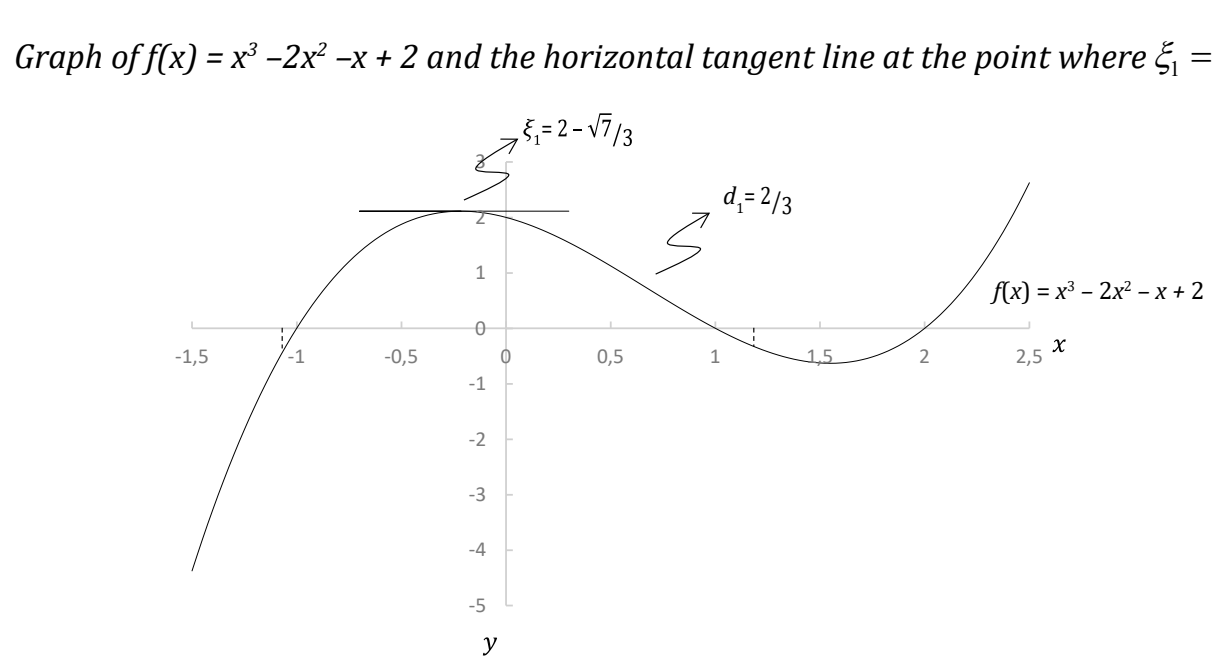

Source: Authors' calculations.

$f^{\prime}(x)$ and $f^{\prime \prime}(x)$ exist and are continuous for all values of $x$. $f$ and $f^{\prime}$ are differentiable on the interval $(-\infty,+\infty)$ and therefore continuous on $(-\infty,+\infty)$. Thus, the conditions (i), (ii) and (iii) of the theorem are satisfied at any interval. Any interval in which the condition (iv) is fulfilled is determined as follows:

$$
\begin{aligned}
& 0=\sin x \\
& x=\sin ^{-1} 0 \\
& x=n \pi, n \in \mathbb{Z}
\end{aligned}
$$

Choosing $a=0$ and $b=4 \pi$.

The condition (v) is satisfied. Since $f$ is differentiable on the interval $(-\infty,+\infty)$, the lateral derivatives evaluated at the extremes of the interval of the condition (vi) are given by:

$$
\begin{aligned}
f_{+}^{\prime}(0) & =f_{-}^{\prime}(0)=f^{\prime}(0) \\
f^{\prime}(0) & =\cos 0=1 \\
f_{-}^{\prime}(4 \pi) & =f_{+}^{\prime}(4 \pi)=f^{\prime}(4 \pi) \\
f^{\prime}(4 \pi) & =\cos 4 \pi=1
\end{aligned}
$$

Therefore, the condition (vi) is fulfilled. From the derivative of $f^{\prime}$ :

$$
f^{\prime \prime}(x)=-\sin x
$$

The points $d_{i}$ in the open interval $(0,4 \pi)$ such that $f^{\prime \prime}\left(d_{i}\right)=0$ are calculated as:

$$
0=-\sin x
$$

$$
\begin{aligned}
& 0=\sin x \\
& x=\sin ^{-1} 0 \\
& x=n \pi, n \in \mathbb{Z}
\end{aligned}
$$

$d_{1}=\pi, d_{2}=2 \pi, d_{3}=3 \pi$. Thus, there are $n=3$ points $d_{i}$ in the interval $(0,4 \pi)$ (condition (vii)). The derivative at the points $d_{i}$ is determined as follows:

$$
\begin{aligned}
f^{\prime}(\pi) & =f^{\prime}(3 \pi)=\cos \pi=\cos 3 \pi=-1 \\
f^{\prime}(2 \pi) & =\cos 2 \pi=1
\end{aligned}
$$

The condition (viii) is satisfied since the derivative of $f$ at the points $d_{i}$ is different from zero, $f^{\prime}\left(d_{i}\right) \neq 0(\mathrm{i}=1,2,3)$

The signs of the derivatives of $f$ at the points $d_{i}$ alternate (condition (ix)). $f^{\prime}(\pi)<0, f^{\prime}(2 \pi)>0, f^{\prime}(3 \pi)<0$.

Then, exist $3+1=4$ numbers $\xi_{i}$ in the interval $(0,4 \pi)$ such that $f^{\prime}\left(\xi_{1}\right)=f^{\prime}\left(\xi_{2}\right)=f^{\prime}\left(\xi_{3}\right)=f^{\prime}\left(\xi_{4}\right)=0$, since:

The signs of the lateral right-hand derivative evaluated at $0, f_{+}^{\prime}(0)>0$ and that of the derivative evaluated at the first point $\pi, f^{\prime}(\pi)<0$ are different, and

The signs of the derivative evaluated at the last point $3 \pi, f^{\prime}(3 \pi)<0$ and that of the lateral left-hand derivative evaluated at $4 \pi, f_{-}^{\prime}(4 \pi)>0$ are different. 
The 4 numbers $\xi_{i}$ in the interval $(0,4 \pi)$ are given by:

$$
\begin{aligned}
f^{\prime}(x) & =\cos x=0 \\
x & =\cos ^{-1} 0 \\
x & =\pi / 2+n \pi, n \in \mathbb{Z}
\end{aligned}
$$

Thus, $\xi_{1}=\pi / 2, \xi_{2}=3 \pi / 2, \xi_{3}=5 \pi / 2, \xi_{4}=7 \pi / 2$.

Figure 8 shows the graph of $f$ and the horizontal tangent lines at the points where $\xi_{1}=\pi / 2, \xi_{2}=3 \pi / 2, \xi_{3}=5 \pi / 2, \xi_{4}=7 \pi / 2$.

\section{Corollary}

Let $f$ be:

$$
f(x)=x^{2}-5 x+5
$$

The derivative of $f$ is:

$$
f^{\prime}(x)=2 x-5
$$

The derivative of $f^{\prime}$ is:

$$
f^{\prime \prime}(x)=2
$$

$f^{\prime}(x)$ and $f^{\prime \prime}(x)$ exist and are continuous for all values of $x$. $f$ and $f^{\prime}$ are differentiable on the interval $(-\infty,+\infty)$ and therefore continuous on $(-\infty,+\infty)$. Thus, the conditions (i), (ii) and (iii) of the theorem are satisfied at any interval. Any interval in which the condition (iv) is fulfilled is determined as follows:

$$
\begin{aligned}
& 1=x^{2}-5 x+5 \\
& 0=x^{2}-5 x+4 \\
& x=\frac{5 \pm \sqrt{25-16}}{2} \\
& x=\frac{5 \pm 3}{2} \\
& x_{1}=1, x_{2}=4
\end{aligned}
$$

Choosing $a=1$ and $b=4$.

The condition (v) is satisfied. From the derivative of $f^{\prime}$ :

$$
f^{\prime \prime}(x)=2
$$

There is no point $d$ in the open interval $(1$, 4) such that $f^{\prime \prime}(d)=0$. Therefore, the condition (vi) is fulfilled. Then, there is only one number $\xi$ in the interval $(1,4)$ such that $f^{\prime}(\xi)=0$. To determine the value of $\xi$, it is considered $f^{\prime}(x)=0$, where the following is obtained:

$$
\begin{aligned}
& 0=2 x-5 \\
& x=5 / 2
\end{aligned}
$$

Figure 9 shows the graph of $f$ and the horizontal tangent line at the point where $\xi=5 / 2$.

Figure 8.

Graph of $f(x)=\sin x$ and the horizontal tangent lines at the points where $\xi_{1}=\pi / 2, \xi_{2}=3 \pi / 2, \xi_{3}=5 \pi / 2, \xi_{4}=7 \pi / 2$

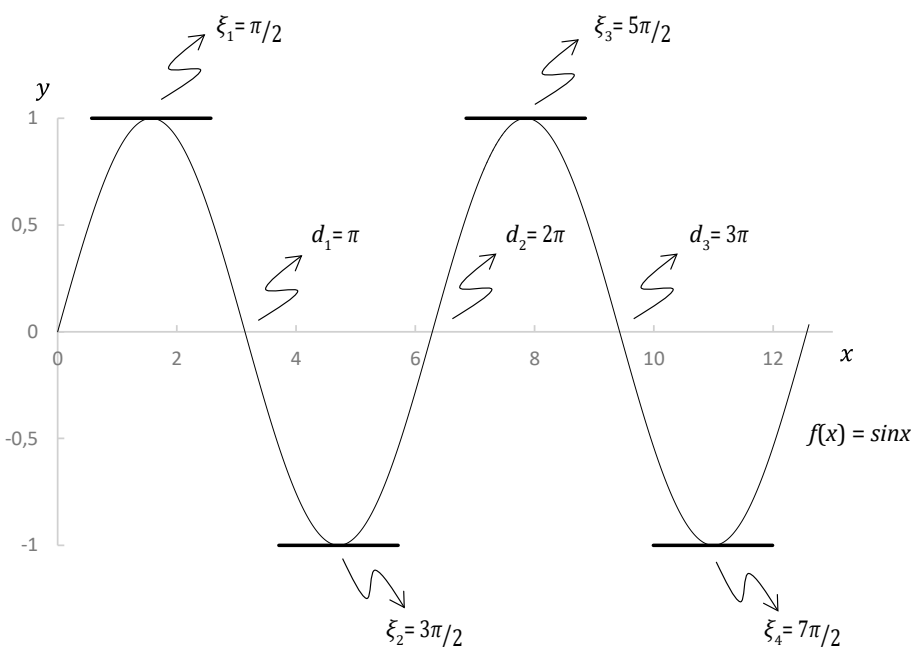

Source: Authors' calculations. 


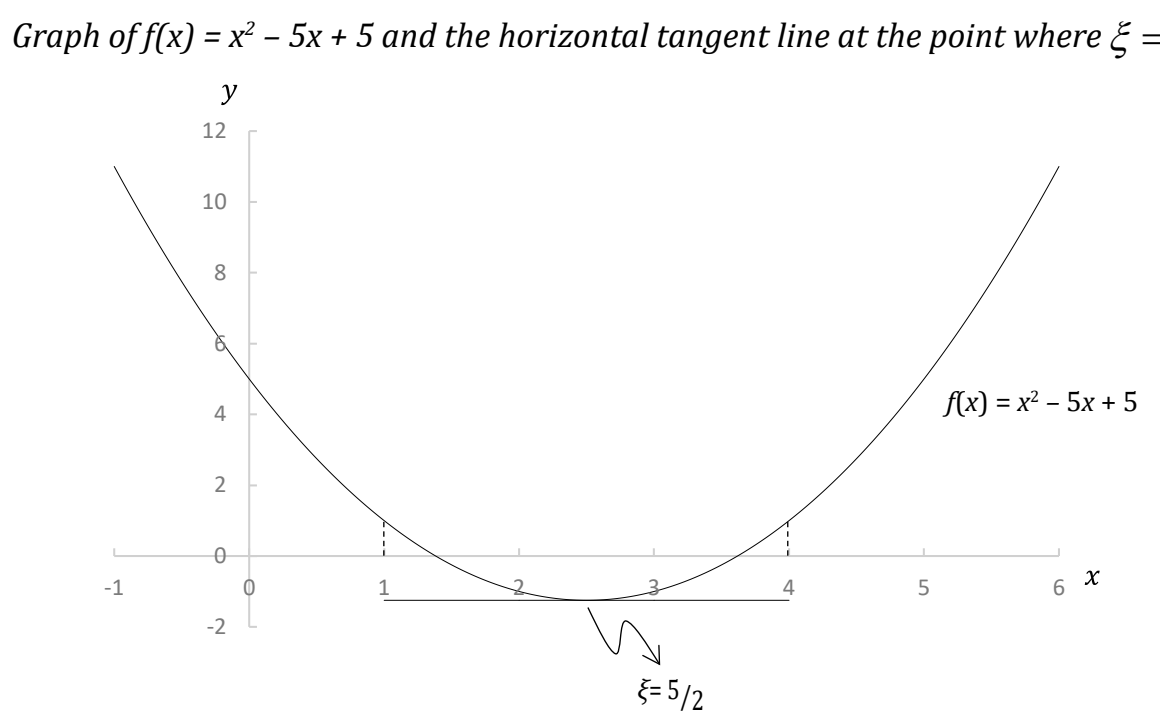

Source: Authors' calculations.

\section{Additional illustrative example}

In this example, a function is presented in which the extension can or cannot be applicable according to the interval choice.

Let $f$ be:

$$
f(x)=\frac{1}{2} x^{2}-\cos x
$$

The derivative of $f$ is:

$$
f^{\prime}(x)=x+\sin x
$$

The derivative of $f^{\prime}$ is:

$$
f^{\prime \prime}(x)=1+\cos x
$$

$f^{\prime}(x)$ and $f^{\prime \prime}(x)$ exist and are continuous for all values of $x$. $f$ and $f^{\prime}$ are differentiable on the interval $(-\infty,+\infty)$ and therefore continuous on $(-\infty,+\infty)$. Thus, the conditions (i), (ii) and (iii) of the theorem are satisfied at any interval. Any interval in which the condition (iv) is fulfilled is determined as follows:

Setting $b=-a$

$$
f(a)=\frac{1}{2} a^{2}-\cos a
$$

$$
\begin{aligned}
& f(b)=f(-a)=\frac{1}{2}(-a)^{2}-\cos (-a) \\
& f(b)=f(-a)=\frac{1}{2} a^{2}-\cos a
\end{aligned}
$$

Thus, $f(a)=f(-a), f$ is an even function.
Choosing any $a$ and $b=-a, f(a)=f(b)$ is obtained.

Two cases are studied:

Case 1: $a=-7 \pi / 6$ and $b=7 \pi / 6$.

Case 2: $a=-19 \pi / 6$ and $b=19 \pi / 6$.

The condition (v) is satisfied. Since $f$ is differentiable on the interval $(-\infty,+\infty)$, the lateral derivatives evaluated at the extremes of the interval of the condition (vi) are given by:

\section{Case 1:}

$$
\begin{aligned}
f_{+}^{\prime}(-7 \pi / 6) & =f_{-}^{\prime}(-7 \pi / 6)=f^{\prime}(-7 \pi / 6) \\
f^{\prime}(-7 \pi / 6) & =-7 \pi / 6+\sin (-7 \pi / 6)=-7 \pi / 6 \\
+1 / 2 & =\frac{3-7 \pi}{6}=-3.165 \\
f_{-}^{\prime}(7 \pi / 6) & =f_{+}^{\prime}(7 \pi / 6)=f^{\prime}(7 \pi / 6) \\
f^{\prime}(7 \pi / 6) & =7 \pi / 6+\sin (7 \pi / 6)=7 \pi / 6-1 / 2 \\
& =\frac{7 \pi-3}{6}=3.165
\end{aligned}
$$

\section{Case 2:}

$f_{+}^{\prime}(-19 \pi / 6)=f_{-}^{\prime}(-19 \pi / 6)=f^{\prime}(-19 \pi / 6)$ 


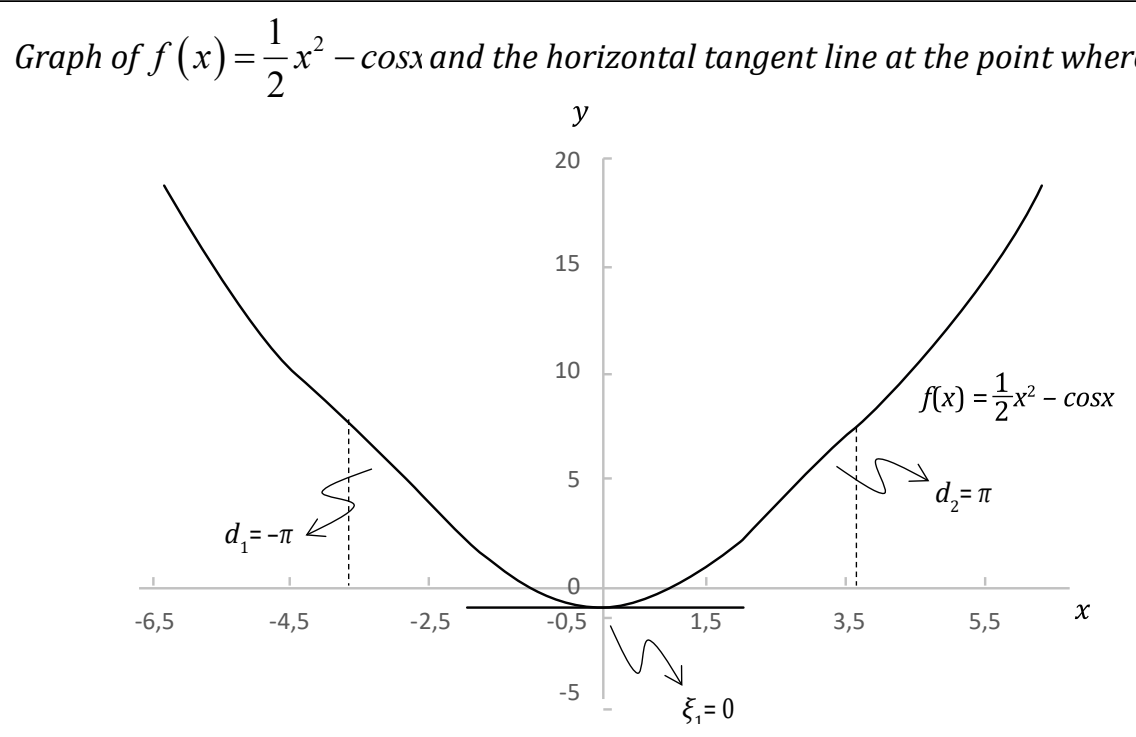

Source: Authors' calculations.

$$
\begin{aligned}
f^{\prime}(-19 \pi / 6) & =-19 \pi / 6+\sin (-19 \pi / 6)= \\
-19 \pi / 6+1 / 2 & =\frac{3-19 \pi}{6}=-9.448 \\
f_{-}^{\prime}(19 \pi / 6) & =f_{+}^{\prime}(19 \pi / 6)=f^{\prime}(19 \pi / 6) \\
f^{\prime}(19 \pi / 6) & =19 \pi / 6+\sin (19 \pi / 6)=19 \pi / 6-1 / 2 \\
& =\frac{19 \pi-3}{6}=9.448
\end{aligned}
$$

Therefore, the condition (vi) is fulfilled. From the derivative of $f^{\prime}$ :

$$
f^{\prime \prime}(x)=1+\cos x
$$

The points $d_{i}$ such that $f^{\prime \prime}\left(d_{i}\right)=0$ are calculated:

$$
\begin{aligned}
0 & =1+\cos x \\
-1 & =\cos x \\
x & =\cos ^{-1}(-1) \\
x & =r \pi, r \text { is odd. }
\end{aligned}
$$

Case 1: $d_{1}=-\pi, d_{2}=\pi$. Thus, there are $n=$ 2 points $d_{i}$ in the interval $(-7 \pi / 6,7 \pi / 6)$.

Case 2: $d_{1}=-3 \pi, d_{2}=-\pi, d_{3}=\pi, d_{4}=3 \pi$ Thus, there are $n=4$ points $d_{i}$ in the interval $(-19 \pi / 6,19 \pi / 6)$.

The derivative at the points $d_{i}$ is determined:
Case 1:

$$
\begin{aligned}
f^{\prime}(-\pi) & =-\pi+\sin -\pi=-\pi \\
f^{\prime}(\pi) & =\pi+\sin \pi=\pi
\end{aligned}
$$

The condition (viii) is satisfied since the derivative of $f$ at the points $d_{i}$ is different from zero, $f^{\prime}\left(d_{i}\right) \neq 0(\mathrm{i}=1,2)$.

Case 2:

$$
\begin{aligned}
f^{\prime}(-3 \pi) & =-3 \pi+\sin -3 \pi=-3 \pi \\
f^{\prime}(-\pi) & =-\pi+\sin -\pi=-\pi \\
f^{\prime}(\pi) & =\pi+\sin \pi=\pi \\
f^{\prime}(3 \pi) & =3 \pi+\sin 3 \pi=3 \pi
\end{aligned}
$$

The condition (viii) is satisfied since the derivative of $f$ at the points $d_{i}$ is different from zero, $f^{\prime}\left(d_{i}\right) \neq 0(\mathrm{i}=1,2,3,4)$.

\section{Case 1}

The signs of the derivatives of $f$ at the points $d_{i}$ alternate (condition (ix)). $f^{\prime}(-\pi)<0, f^{\prime}(\pi)>0$.

Then, there exist $2-1=1$ number $\xi_{1}$ in the interval $(-7 \pi / 6,7 \pi / 6)$ such that $f^{\prime}\left(\xi_{1}\right)=0$, since:

The signs of the lateral right-hand derivative evaluated at $-7 \pi / 6^{\prime} f_{+}^{\prime}(-7 \pi / 6)<0$ and that of the derivative evaluated at the first point $-\pi$, $f^{\prime}(-\pi)<0$ are the same, and 
The signs of the derivative evaluated at the last point $\pi, f^{\prime}(\pi)>0$ and that of the lateral lefthand derivative evaluated at $7 \pi / 6, f_{-}^{\prime}(7 \pi / 6)>0$ are the same (Part 2a).

The number $\xi_{1}$ in the interval $(-7 \pi / 6,7 \pi / 6)$ is given by:

$$
\begin{aligned}
f^{\prime}(x) & =x+\sin x=0 \\
-x & =\sin x \\
x & =0
\end{aligned}
$$

Thus, $\xi_{1}=0$.

Figure 10 shows the graph of $f$ and the horizontal tangent line at the point where $\xi_{1}=0$.

Case 2

The signs of the derivatives of $f$ at the points $d_{i}$ do not alternate (condition (ix)). $f^{\prime}(-3 \pi)<0$, $f^{\prime}(-\pi)<0, f^{\prime}(\pi)>0, f^{\prime}(3 \pi)>0$. The extension is not applicable. Although there are four points $d_{i}$, there is only one number $\xi_{1}$ in the interval $(-19 \pi / 6,19 \pi / 6)$ such that $f^{\prime}\left(\xi_{1}\right)=0$.

\section{A SIMPLE EXTENSION OF ROLLE'S THEOREM AND ITS RELATION WITH MULTIPLE INTERNAL RATES OF RETURN (IRR)}

A company is considering to buy a new machine for its production plant. The new machine will increase the productivity of the company and reduce the labor cost. The cost of the machine is distributed in several years as follows (values in thousands of currency units):

\begin{tabular}{|c|c|c|c|}
\hline 0 & 1 & 2 & 3 \\
\hline 12 & 10 & 40 & 10 \\
\hline
\end{tabular}

The associated benefits are summarized in the following table:

\begin{tabular}{|c|c|c|c|}
\hline 1 & 2 & 3 & 4 \\
\hline 45 & 10 & 5 & 13 \\
\hline
\end{tabular}

The company's management establishes a minimum required rate of return of $8 \%$. The project of the new machine for the production plant is evaluated using the internal rate of return (IRR).

The expected net cash flows are presented in Figure 11. The net present value (NPV) is the difference between the present value of cash inflows and outflows (Cissell et al., 1990; Vélez Pareja, 2002). First, the net present value (NPV) is calculated.

Cash flows are discounted at the discount rate:

$$
N P V(i)=-12+35(1+i)^{-1}-30(1+i)^{-2}-5(1+i)^{-3}
$$
$+13(1+i)^{-4}$

Expressing the binomials with positive exponents:

$$
\begin{aligned}
N P V(i)=-12 & +\frac{35}{(1+i)}-\frac{30}{(1+i)^{2}}-\frac{5}{(1+i)^{3}} \\
& +\frac{13}{(1+i)^{4}}
\end{aligned}
$$

Thus:

$$
\begin{gathered}
N P V(i)=\frac{-12(1+i)^{4}+35(1+i)^{3}-30(1+i)^{2}}{(1+i)^{4}} \\
-5(1+i)+13
\end{gathered}
$$

Using the binomial theorem:

$$
\begin{aligned}
& (1+i)^{4}=1+4 i+6 i^{2}+4 i^{3}+i^{4} \\
& (1+i)^{3}=1+3 i+3 i^{2}+i^{3} \\
& (1+i)^{2}=1+2 i+i^{2}
\end{aligned}
$$

Thus:

$$
\begin{gathered}
N P V(i)=\frac{-12\left(1+4 i+6 i^{2}+4 i^{3}+i^{4}\right)}{+35\left(1+3 i+3 i^{2}+i^{3}\right)-30\left(1+2 i+i^{2}\right)-5(1+i)+13} \\
\frac{+4 i+6 i^{2}+4 i^{3}+i^{4}}{1+4 i}
\end{gathered}
$$

Solving the grouping symbols:

$$
\begin{gathered}
N P V(i)=\frac{-12-48 i-72 i^{2}-48 i^{3}-12 i^{4}+}{35+105 i+105 i^{2}+35 i^{3}-30-60 i-30 i^{2}} \\
\frac{3+4 i+6 i^{2}+4 i^{3}+i^{4}}{-5-5 i+13}
\end{gathered}
$$


Figure 11.

Cash flow diagram to calculate the net present value (NPV) and the internal rate of return (IRR).

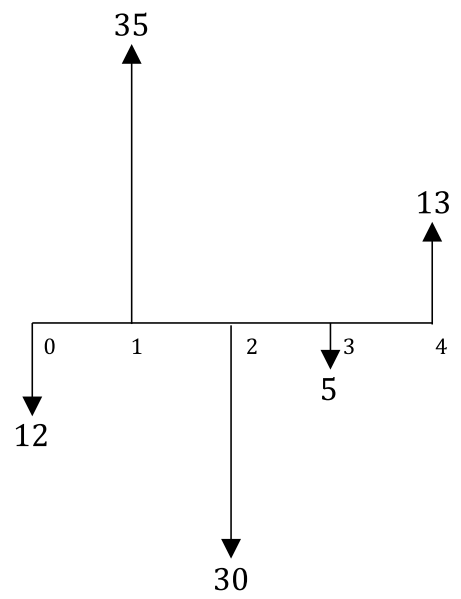

Source: Authors' calculations.

Simplifying the expression:

$$
N P V(i)=\frac{1-8 i+3 i^{2}-13 i^{3}-12 i^{4}}{1+4 i+6 i^{2}+4 i^{3}+i^{4}}
$$

The internal rate of return (IRR) is a discount rate that makes the net present value (NPV) of all cash flows equal to zero (Cissell et al., 1990; Vélez Pareja, 2002):

$$
0=N P V(i)=\frac{1-8 i+3 i^{2}-13 i^{3}-12 i^{4}}{1+4 i+6 i^{2}+4 i^{3}+i^{4}}
$$

Thus:

$$
0=p(i)=1-8 i+3 i^{2}-13 i^{3}-12 i^{4}
$$

This simple extension of Rolle's theorem allows determining the amount of numbers $\xi_{i}$ in which $f^{\prime}\left(\xi_{i}\right)=0$ in a given interval, using the characteristics of the function in that interval. So, the number of roots of $p(i)$ can be determined using the characteristics of the function $P(i)$. Where $P^{\prime}(i)=p(i)$.

The function $P(i)$ is calculated as follows:

$$
P(i)=\int[p(i)] d i=\int\left(1-8 i+3 i^{2}-13 i^{3}-12 i^{4}\right) d i
$$

Thus:

$$
P(i)=i-4 i^{2}+i^{3}-\frac{13}{4} i^{4}-\frac{12}{5} i^{5}+a
$$

Where $a$ is a constant. If $a=0$, the following is obtained:

$$
P(i)=i-4 i^{2}+i^{3}-\frac{13}{4} i^{4}-\frac{12}{5} i^{5}
$$

The derivative of $p(i)$ is:

$$
P^{\prime \prime}(i)=p^{\prime}(i)=-8+6 i-39 i^{2}-48 i^{3}
$$

$P^{\prime}(i)$ and $P^{\prime \prime}(i)$ exist and are continuous for all values of $i$. $P$ and $P^{\prime}$ are differentiable on the interval $(-\infty,+\infty)$ and therefore continuous on $(-\infty,+\infty)$. Thus, the conditions (i), (ii) and (iii) of the theorem are satisfied at any interval. Any interval in which the condition (iv) is fulfilled is determined as follows:

$$
-6=i-4 i^{2}+i^{3}-\frac{13}{4} i^{4}-\frac{12}{5} i^{5}
$$

Two solutions are -1.903 and 0.937 .

Choosing $a=-1.903$ and $b=0.937$.

The condition (v) is satisfied. Since $P$ is differentiable on the interval $(-\infty,+\infty)$, the lateral derivatives evaluated at the extremes of the interval of the condition (vi) are given by:

$$
\begin{gathered}
P_{+}^{\prime}(-1.903)=P_{-}^{\prime}(-1.903)=P^{\prime}(-1.903) \\
P^{\prime}(-1.903)=1-8(-1.903)+3(-1.903)^{2} \\
-13(-1.903)^{3}-12(-1.903)^{4}=-40.697 \\
P_{-}^{\prime}(0.937)=P_{+}^{\prime}(0.937)=P^{\prime}(0.937) \\
P^{\prime}(0.937)=1-8(0.937)+3(0.937)^{2} \\
-13(0.937)^{3}-12(0.937)^{4}=-23.807
\end{gathered}
$$


Therefore, the condition (vi) is fulfilled. From the derivative of $P^{\prime}$ :

$$
P^{\prime \prime}(i)=-8+6 i-39 i^{2}-48 i^{3}
$$

The points $d_{i}$ in the open interval $(-1.903,0.937)$ such that $P^{\prime \prime}\left(d_{i}\right)=0$ are calculated:

$$
\begin{aligned}
0 & =-8+6 i-39 i^{2}-48 i^{3} \\
i & =-1.074
\end{aligned}
$$

$d_{1}=-1.074$ Thus, there is $n=1$ point $d$ in the interval $(-1.903,0.937)$ (condition (vii)). The derivative at the point $d$ is determined as:

$$
\begin{gathered}
P^{\prime}(-1.074)=1-8(-1.074)+3(-1.074)^{2} \\
-13(-1.074)^{3}-12(-1.074)^{4}=13.191
\end{gathered}
$$

The condition (viii) is satisfied since the derivative of $P$ at the point $d$ is different from zero, $P^{\prime}\left(d_{i}\right) \neq 0(i=1)$.

$d_{1}=-1.074$ are both the first and the last point $d$. The condition (ix) is not applicable.

Then, there exist $1+1=2$ numbers $\xi_{i}$ in the interval $(-1.903,0.937)$ such that $P^{\prime}\left(\xi_{1}\right)=P^{\prime}\left(\xi_{2}\right)=0$ since:

The signs of the lateral right-hand derivative evaluated at $-1.903, P_{+}^{\prime}(-1.903)<0$ and that of the derivative evaluated at the first point -1.074 , $P^{\prime}(-1.074)>0$ are different, and

The signs of the derivative evaluated at the last point $-1.074, P^{\prime}(-1.074)>0$ and that of the lateral left-hand derivative evaluated at 0.937 , $P_{-}^{\prime}(0.937)<0$ are different.

The two numbers $\xi_{i}$ in the interval $(-1.903$, $0.937)$ are given by:

$$
\begin{gathered}
P^{\prime}(i)=p(i)=1-8 i+3 i^{2}-13 i^{3}-12 i^{4}=0 \\
i_{1}=-1.546, i_{2}=0.127
\end{gathered}
$$$$
\text { Thus, } \xi_{1}=-1.546, \xi_{2}=0.127 \text {. }
$$

Figure 12 shows the graph of $P$ and the horizontal tangent lines at the points where $\xi_{1}=-1.546$, $\xi_{2}=0.127$.

Since $P^{\prime}(i)=\mathrm{p}(i)$, there are two internal rates of return (IRR) in the open interval $(-1.903,0.937)$, $I R R_{1}=-1.546, I R R_{2}=0.127$. Figure 13 shows the graph of the net present value (NPV) and two internal rates of return (IRR) in the open interval $(-1.903,0.937)$.

According to this result, the project of the new machine for the production plant is acceptable since the internal rate of return calculated for the project

Figure 12.

Graph of $P(i)=i-4 i^{2}+i^{3}-\frac{13}{4} i^{4}-\frac{12}{5} i^{5}$ and the horizontal tangent lines at the points where $\xi_{1}=-1.546$,

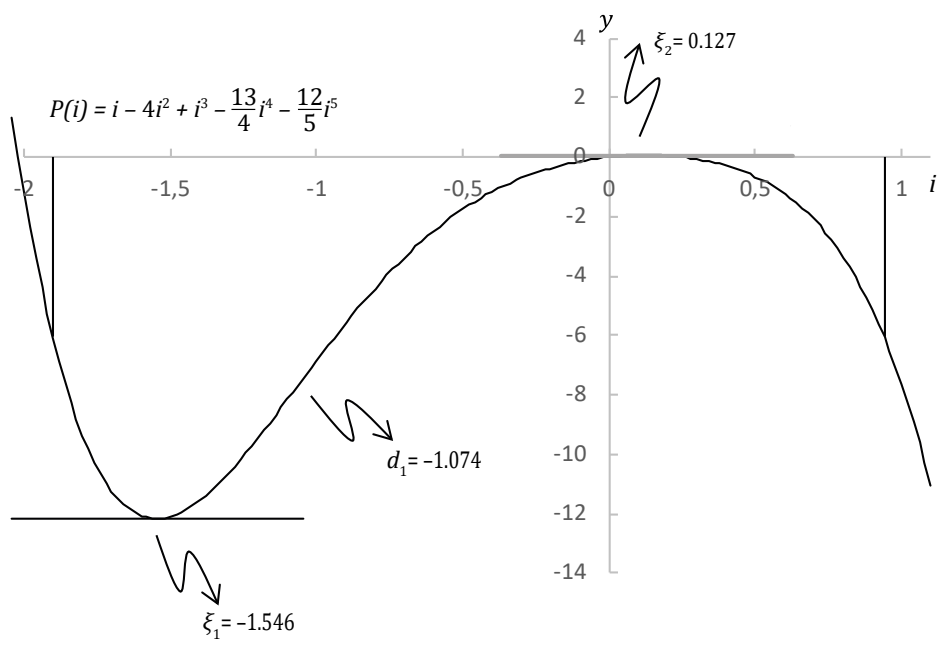

Source: Authors' calculations. 
Figure 13.

Graph of the net present value (NPV) and two internal rates of return (IRR) in the open interval $(-1.903,0.937)$.

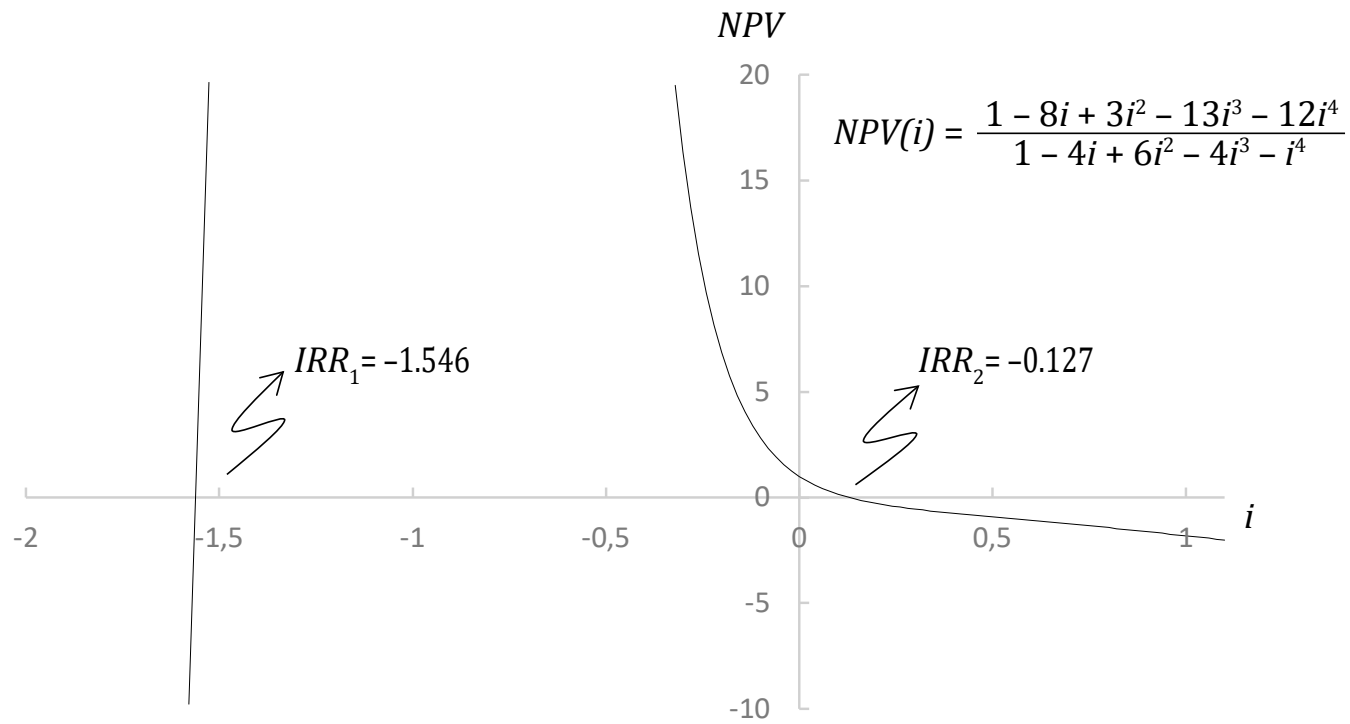

Source: Authors' calculations.

$(12.7 \%)$ is higher than the minimum required rate of return (8\%) (Cissell et al., 1990; Vélez Pareja, 2002).

\section{CONCLUSIONS}

This paper has stated and proved a simple extension of Rolle's theorem. It has also presented the geometric interpretation of the theorem. This extension allows determining the amount of numbers $\xi_{i}$ in which $f^{\prime}\left(\xi_{i}\right)=0$ in a given interval, using the characteristics of the function $f$ in that interval. Illustrative examples have been solved for each case that can be obtained to show the application of the theorem. Financial evaluation indicates whether a project will contribute to creating value and generating profit. The most widely used investment evaluation techniques are net present value (NPV) and internal rate of return (IRR).

This theorem has been used to calculate the amount of IRR in a non-conventional cash flow. The NPV expression for the non-conventional cash flow has also been determined. The characteristics of the function $P$ derived from the net present value expression have allowed estimating the amount of internal rates of return. The comparison of IRR with the minimum required rate of return supports the investment decision. If the internal rate of return on a project is greater than the minimum required rate of return, then the project should be accepted; otherwise, the project should be rejected. 


\section{REFERENCES}

1. Cissell, R., Cissell H., \& Flaspohler D. C. (1990). Mathematics of Finance. Boston: Houghton Mifflin Co.

2. Leithold, L. (1995). The Calculus 7. New York: HarperCollins College Publishers.

3. Martínez de la Rosa, F. (2008). Panorámica de los teoremas de valor medio. Miscelánea matemática, 47, 23-38. http://www.miscelaneamatematica.org/Misc47/4703.pdf

4. Pérez-Chavela E. \& Petakos K. (2009). Una nota sobre el teorema de Rolle. Miscelánea matemática, 50, 89-94.

5. Tan, S. T. (2011). Calculus: Early Transcendentals. Boston: Cengage Learning.

6. Vélez Pareja, I. A. (2002). Decisiones de inversión. Enfocado a la valoración de empresas. Bogotá: CEJA. 